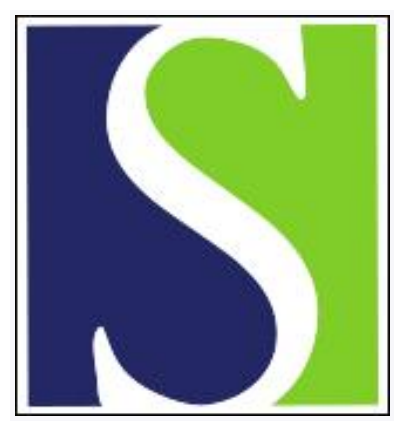

Scand J Work Environ Health 1992;18(6):361-367

https://doi.org/10.5271/sjweh.1561

Issue date: 01 Dec 1992

Sources of variance in exposure to postural load on the back in occupational groups.

by Burdorf $A$

Affiliation: Institute of Occupational Health, Erasmus University, Rotterdam, The Netherlands.

The following articles refer to this text: 2010;36(1):3-24;

2014;40(3):252-265

This article in PubMed: www.ncbi.nlm.nih.gov/pubmed/1485161

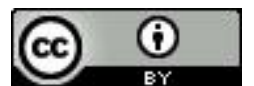




\title{
Sources of variance in exposure to postural load on the back in occupational groups
}

\author{
by Alex Burdorf, MSc ${ }^{1}$
}

\begin{abstract}
BURDORF A. Sources of variance in exposure to postural load on the back in occupational groups. Scand $J$ Work Environ Health 1992;18:361-7. The variability of exposure to postural load on the back was studied in five occupational groups. A random sample of workers in each group was observed for two periods of 30 min during a shift, their posture being classified every $20 \mathrm{~s}$. The estimated percentage of time spent in trunk flexion and rotation formed the principal measures of exposure. The partitioning of the total variability of exposure showed that occupational group status was the principal source of variance. The between-group variance accounted for 47 and $72 \%$ of the total variability of exposure to trunk flexion and rotation, respectively. The corresponding percentages were 29 and $16 \%$ for the within-worker variance of trunk flexion and rotation and 24 and $12 \%$ for the between-worker variance. This type of analysis of the sources of exposure variability may help to establish appropriate measurement strategies for exposure to postural load on the back in epidemiologic studies on low-back pain.
\end{abstract}

Key terms: between-worker variance, measurement, within-worker variance.

Postural load has been recognized as an important occupational risk factor for low-back pain (1-3). Biomechanical modeling has demonstrated that any deviation from anatomically neutral trunk postures increases the load on the lumbar spine (4). Some epidemiologic studies have shown that nonneutral postures of the trunk, for example, bending and twisting, are significantly related to the risk of low-back pain (5-7). However, the epidemiologic evidence is limited since other studies have failed to find any association between frequent bending or the rotation of the trunk during work and low-back pain $(8,9)$. Associations between specific aspects of postural load and the development of disorders of the back could remain undetected because of a misclassification of exposure (10).

It has been argued that in many epidemiologic studies on disorders of the back in occupational groups the quality of exposure data is poor (11). Often the measurement of exposure has been restricted to surrogates such as occupational title or job categorization. In a limited number of studies quantitative measurement methods have been applied to assess exposure to nonneutral trunk postures during work (11).

Basically, two approaches of exposure assessment can be considered (12). In the first approach each worker of the population under study is monitored.

\footnotetext{
1 Institute of Occupational Health, Erasmus University, Rotterdam, The Netherlands.
}

Reprint requests to: Mr A Burdorf, Institute of Occupational Health, Erasmus University, Medical Faculty, PO Box 1738, DR-3000 Rotterdam, The Netherlands.
Since measurement of nonneutral trunk postures is time-consuming and labor intensive, this measurement strategy has been applied in a few studies only $(5,6$, 13). In the second approach, more common in epidemiologic surveys, a random sample of workers in each occupational group under study is monitored. Subsequently, the average values of the parameters measured are used to characterize the postural load of the workers within each occupational group. An underlying assumption of this measurement strategy is that the mean exposure of the workers sampled is equal to the average of the whole occupational group.

In epidemiologic studies based on a comparison of occupations with clearly distinguishable levels of exposure, this second approach requires that differences in exposure among occupations be substantially larger than differences among workers within the occupation, that is, that the exposure variability within occupational groups is small compared with differences between occupational groups. This assumption usually implies exposure groups with workers more or less uniformly exposed, often referred to as homogeneous exposure groups. Because not only workers of groups are sampled, but also specific parts of worker's exposure experience, the magnitude of exposure variability at the individual level is important. Since it is largely unknown whether an individual's distribution of nonneutral trunk postures within a shift and between different shifts varies considerably, repeated measurements of the same individuals have to be performed. To obtain an unbiased estimator of true exposure, the measurement strategy has to take into account all relevant sources of variability of exposure. Therefore, an evaluation of the components of exposure variability is necessary, partitioning the variability into the between-group variance, the between- 
worker variance, and the within-worker variance (14). Ultimately, assessment of these components of exposure variability can enable the investigator to evaluate the attenuation of associations between exposure and health outcome.

The goal of the current study was (i) to identify the components of exposure variability for nonneutral trunk postures in different occupational groups and (ii) to investigate consequences of exposure variability for the assessment of exposure to postural load on the back in occupational epidemiology. Since bending and rotation of the trunk are frequently observed postures in many work situations, the choice was made to assess postural load due to postures of the trunk in flexion or rotation.

\section{Subjects and methods}

\section{Subjects}

Five occupational groups were selected in three different companies. The first group was obtained as a random sample of 21 of 95 straddle-carrier drivers at a terminal in the port of Rotterdam. Their tasks involved the transport of freight containers from the quay to the stack. On the average they handled 30 to 40 containers every hour. They performed this work in a sedentary posture.

The second occupational group came from the same company and consisted of 20 crane operators who were randomly selected from 94 subjects in the same job. The task of the operators of overhead traveling cranes was to load and unload freight containers from a ship to the quay. Under normal conditions they handled 40 to 60 containers every hour. They also performed their work in a sedentary posture.

The third occupational group comprised 10 of 86 office workers in this transport company. Their activities involved normal clerical tasks, mainly performed in a sedentary posture at a desk.

The fourth occupational group was obtained as a sample of 14 of 24 sawyers and woodworking machinists in a woodworking company. These workers operated various woodcutting machines. Their task was either to feed wooden shelves into a machine or to remove wooden shelves from a machine. These tasks were machine-paced and of repetitive nature with work cycles that often lasted less than $1 \mathrm{~min}$. Their work was predominantly performed in a standing posture, mainly close to the woodcutting machine.

The fifth group consisted of 12 of 50 packers in a large auction of flowers. Their activities encompassed several tasks, such as the assembly of prefabricated boxes and the collection and delivery of boxes to the various departments of the auction. A work cycle could vary from $20 \mathrm{~s}$ to $10 \mathrm{~min}$, according to the task performed. Their work was mainly performed in a standing posture, not necessarily restricted to one place.

\section{Method for assessing postural load}

The assessment of the postural load on the back was focused on nonneutral postures of the trunk in the sagittal plane (flexion) and the transversal plane (axial rotation). Deviations from straight upright posture of the trunk were classified as forward flexion ( $>20$ degrees bent forward) or axial rotation ( $>20$ degrees twisted). The method of measurement used was the Ovako working posture analyzing system (OWAS), which was slightly modified to separate flexion and rotation during the observations (15). Observations were made at the workplace every $20 \mathrm{~s}$ during two periods of $30 \mathrm{~min}$. Thus 90 observations were collected from each worker during each measurement. To decrease the interobserver variability, all of the measurements in a specific company were performed by one person. The exposure measure presented is the percentage of the total worktime spent with the trunk in flexion or rotation.

The duration of measurement was $30 \mathrm{~min}$. In most occupational groups this time span will cover at least 15 complete work cycles. If the work cycle is the most important source of variance, the characterization of trunk postures during a number of subsequent work cycles is assumed to assess adequately the postural back load to which a worker is exposed during a typical workday. The first measurement was conducted in the first hours of the shift, and the second measurement took place during the latest hours of the same shift. This procedure of repeated measurement provided information concerning the personal distribution of exposure to postural load within a shift. The assumption was made that the variance of exposure to postural load within a shift markedly exceeded the shift-to-shift variance of exposure. Therefore, the worker's distribution of exposure to postural load within a shift (the within-shift variance) was used as a proxy for the "within-worker distribution" of postural load.

\section{Exposure characteristics of the occupational groups}

The measurements of the average percentages of time spent in trunk flexion and trunk rotation were the principal measures of exposure to postural load on the back. The distribution of the exposure measurements in each occupational group was evaluated, and six out of ten distributions differed significantly from the normal distribution. Therefore, simple log-transformations were performed which markedly reduced the skewness of the distributions of the exposure variables within each occupational group. Eight of the ten distributions of log-transformed data could be adequately described by a normal distribution. For reason of comparability, log-transformations were performed on all of the measurements. This procedure allowed the normal distribution to be used in the statistical methods. For each occupational group the following descriptive statistics of measures of postural load are 
presented: the arithmetic mean, the geometric mean, the geometric standard deviation (GSD), and the range.

To study whether classification into groups by occupational title was justified, the homogeneity of exposure to postural load in each group was assessed. The first approach was to calculate the geometric standard deviation of the distribution of the worker's mean exposures within each occupational group. The geometric standard deviation of the between-worker variance was derived directly from the analysis of variance of the log-transformed exposure data by the equation $\mathrm{GSD}=\exp \left(\mathrm{SD}_{\mathrm{L}, \mathrm{w}}\right)$ (16). Since this parameter is somewhat difficult to interpret, the between-worker variance was also expressed by the ratio of the 97.5 th percentile to the 2.5 th percentile of the distribution of the worker's mean exposures, denoted by the range ratio $R_{0.95}$. The range ratio can be calculated by the equation $\mathrm{R}_{0.95}=\exp \left(3.92 \cdot \mathrm{SD}_{\mathrm{L}, \mathrm{w}}\right)$. The second approach was to calculate the between-worker and within-worker variance in each occupational title group. If the between-worker variance was large compared with the within-worker variance, the workers were not uniformly exposed. A useful parameter is the variance ratio $\lambda$, the ratio of the within-worker and the betweenworker variance (12). The third approach was to calculate the different components of the exposure variability and to evaluate the contribution of each source of variance to the total variance in the population under study. An analysis of variance was performed to calculate the proportion of variance due to the occupational groups, to the workers within the groups, and to the individual workers within a shift.

\section{Statistical methods}

To test whether measurements within each occupational group were normally distributed, Shapiro \& Wilks statistics were calculated (17).

An analysis of variance was used to separate the total variance of the measurements into its various components. A one-way analysis of variance with repeated measurements was used to estimate the magnitude of both the between-worker and within-worker variance for each occupational group under study. A hierarchical classification was regarded as the most appropriate, in which a population (the occupational group) was sampled a number of times (the workers) and repeated measurements were carried out on each worker. The hierarchical classification is alternatively called a nested classification $(18,19)$. A random-effect model was used since the two periods of observation of each worker were assumed to be drawn at random from the total distribution of parts of shifts. Similarly, the selected workers were regarded as random elements from the total population of workers in their occupational group. The analysis of variance for $n$ repeated measurements on $q$ workers is summarized in table 1 . The mean squares (MS) are estimates of the expected variances $\mathrm{E}(\mathrm{MS})$ which can be used to partition the total variance into the between-worker and withinworker variance $(18,19)$.

To determine the influence of the occupational title group, the individual worker and the parts of the shift on the exposure to postural load on the back, a twoway analysis of variance with repeated measurements was performed. Again, a hierarchical classification was used with a random-effect model. The first underlying assumption of this design was that the group factor was random; since no a priori assumption was made on the level of exposure in each group, the groups could be regarded as a random sample from an almost infinite population of occupational groups. In this design the workers were nested within the levels of the group factor. The idea of nesting is that the different levels of the group factor contain different workers. The second underlying assumption was that the group of workers consisted of a random sample of all possible workers in each occupational group. The third assumption was that the measurements of a worker's exposure to postural load were independent and normally distributed. For the general two-way analysis of variance with $p$ levels of the factor A (group), $q$ levels of the nested factor B (worker), and $n$ repeated measurements at each level of factor $B$, the analysis of variance is summarized in table $2(18,19)$. The mean squares were used to estimate the between-group variance and the between-worker and within-worker variance. Since the number of workers in each occupational group was not equal, a so-called unbalanced design was used. Unbiased estimates for the variance components can be computed similarly to a balanced design. The degrees of freedom associated with the between-group variance are calculated as a kind of average of the numbers of measurements per group (18).

The data analyses were performed with SAS (statistical analysis system) software. The analysis of variance was carried out with the procedure Proc Nested, which conveniently computes the different components of variance. The data used in the analysis of var-

Table 1. One-way analysis of variance with repeated measurements on the same worker. ( $\sigma_{\mathrm{s}}^{2}=$ between parts-of-shift variance $=$ within-worker variance, $\sigma_{w}^{2}=$ between-worker variance, $q=$ number of workers, $n=$ number of repeated measurements per worker)

\begin{tabular}{lllll}
\hline Sources of variance & $\begin{array}{l}\text { Sum of } \\
\text { squares }\end{array}$ & $\begin{array}{l}\text { Degrees of } \\
\text { freedom }\end{array}$ & Mean square & $\begin{array}{l}\text { Expected mean } \\
\text { square }\end{array}$ \\
\hline Between groups & $\mathrm{SS}_{\mathrm{b}, \mathrm{w}}$ & $\mathrm{q}-1$ & $\mathrm{SS}_{\mathrm{b}, \mathrm{w}} /(\mathrm{q}-1)$ & $\sigma_{\mathrm{s}}^{2}+\mathrm{n \sigma}_{\mathrm{w}}^{2}$ \\
Between parts of shift within workers & $\mathrm{SS}_{\mathrm{b}, \mathrm{s}}$ & $\mathrm{q}(\mathrm{n}-1)$ & $\mathrm{SS}_{\mathrm{b}, \mathrm{s}} / \mathrm{q}(\mathrm{n}-1)$ & $\sigma_{\mathrm{s}}^{2}$ \\
\hline
\end{tabular}


Table 2. Two-way analysis of variance with repeated measurements on the same worker, who is nested within the group factor. $\left(\sigma_{\mathrm{s}}^{2}=\right.$ between parts-of-shift variance $=$ within-worker variance, $\sigma_{\mathrm{w}}^{2}=$ between-worker variance, $\sigma_{\mathrm{g}}^{2}=$ between-group variance, $p=$ number of groups, $q=$ number of workers per group, $n=$ number of repeated measurements per worker)

\begin{tabular}{|c|c|c|c|c|}
\hline Sources of variance & $\begin{array}{l}\text { Sum of } \\
\text { squares }\end{array}$ & $\begin{array}{l}\text { Degrees of } \\
\text { freedom }\end{array}$ & Mean square & $\begin{array}{l}\text { Expected mean } \\
\text { square }\end{array}$ \\
\hline Between groups & $\mathrm{SS}_{\mathrm{b}, \mathrm{g}}$ & $p-1$ & $S S_{b, g} /(p-1)$ & $\sigma_{s}^{2}+n \sigma_{w}^{2}+n q \sigma_{g}^{2}$ \\
\hline Between workers within groups & $\mathrm{SS}_{\mathrm{b}, \mathrm{w}}$ & $p(n-1)$ & $S S_{b, w} / p(n-1)$ & $\sigma_{\mathrm{s}}^{2}+n \sigma_{\mathrm{w}}^{2}$ \\
\hline Between parts of shift within workers & $\mathrm{SS}_{\mathrm{b}, \mathrm{s}}$ & $p q(n-1)$ & $\mathrm{SS}_{\mathrm{b}, \mathrm{s}} / \mathrm{pq}(\mathrm{n}-1)$ & $\sigma_{\mathrm{s}}^{2}$ \\
\hline
\end{tabular}

Table 3. Results of measurements of percentage of worktime in trunk flexion by occupational title group. (AM =arithmetic mean, $\mathrm{GM}=$ geometric mean, $\mathrm{GSD}=$ geometric standard deviation)

\begin{tabular}{lcccrr}
\hline Occupational title group & $\begin{array}{c}\text { Number of } \\
\text { measurements }\end{array}$ & $\begin{array}{c}\text { AM } \\
(\%)\end{array}$ & $\begin{array}{c}\text { GM } \\
(\%)\end{array}$ & GSD & $\begin{array}{c}\text { Range } \\
(\%)\end{array}$ \\
\hline Straddle-carrier drivers & 42 & 5.2 & 3.0 & 3.9 & $0.1-18.0$ \\
Crane operators & 40 & 33.3 & 26.8 & 2.2 & $4.0-60.0$ \\
Office workers & 20 & 25.1 & 22.0 & 1.7 & $10.0-52.0$ \\
Woodworking machinists & 28 & 13.4 & 8.0 & 3.0 & $1.0-49.0$ \\
Packers & 24 & 11.7 & 10.6 & 1.6 & $4.0-28.0$ \\
\hline
\end{tabular}

Table 4. Results of measurements of percentage of worktime with trunk rotation by occupational title group. (AM $=$ arithmetic mean, $\mathrm{GM}=$ geometric mean, $\mathrm{GSD}=$ geometric standard deviation)

\begin{tabular}{lcccrr}
\hline Occupational title group & $\begin{array}{c}\text { Number of } \\
\text { measurements }\end{array}$ & $\begin{array}{c}\text { AM } \\
(\%)\end{array}$ & $\begin{array}{c}\text { GM } \\
(\%)\end{array}$ & GSD & $\begin{array}{c}\text { Range } \\
(\%)\end{array}$ \\
\hline Straddle-carrier drivers & 42 & 39.0 & 35.9 & 1.6 & $12.7-58.0$ \\
Crane operators & 40 & 3.0 & 1.8 & 3.0 & $0.1-18.0$ \\
Office workers & 20 & 6.2 & 4.7 & 2.4 & $0.7-14.3$ \\
Woodworking machinists & 28 & 8.6 & 6.6 & 2.7 & $0.1-19.0$ \\
Packers & 24 & 27.4 & 25.3 & 1.5 & $9.0-51.0$ \\
\hline
\end{tabular}

Table 5. Between-worker variance $\left(G S D_{b, w}\right)$, range ratio $\left(R_{0.95}\right)$, and variance ratio $(\lambda)$ for the log-transformed distribution of trunk flexion and trunk rotation by occupational title group. [GSD, $w=$ geometric standard deviation of the between-worker variance $(\operatorname{expSD} L, w), \lambda=$ variance ratio $\left(\sigma_{S}^{2} / \sigma_{\mathrm{w}}^{2}\right), R_{0.95}=$ ratio of 97.5 th percentile to the 2.5 percentile $\left(\exp \left(3.92 \cdot \mathrm{SD}_{\mathrm{L}}, \mathrm{w}\right)\right]$

\begin{tabular}{|c|c|c|c|c|c|c|c|}
\hline \multirow{2}{*}{ Occupational title group } & \multirow{2}{*}{$\begin{array}{l}\text { Number of } \\
\text { measurements }\end{array}$} & \multicolumn{3}{|c|}{ Trunk flexion } & \multicolumn{3}{|c|}{ Trunk rotation } \\
\hline & & $\mathrm{GSD}_{\mathrm{b}, \mathrm{w}}$ & $\mathrm{R}_{0.95}$ & $\lambda$ & $\mathrm{GSD}_{\mathrm{b}, \mathrm{w}}$ & $\mathrm{R}_{0.95}$ & $\lambda$ \\
\hline Straddle-carrier drivers & 42 & 2.0 & 14.7 & 3.0 & 1.5 & 5.1 & 0.2 \\
\hline Crane operators & 40 & 2.1 & 16.9 & 0.3 & 1.7 & 7.4 & 3.6 \\
\hline Office workers & 20 & 1.5 & 4.6 & 1.0 & 2.1 & 17.7 & 0.5 \\
\hline Woodworking machinists & 28 & 2.5 & 35.9 & 0.5 & 2.1 & 18.8 & 0.8 \\
\hline Packers & 24 & 1.3 & 2.5 & 2.8 & 1.2 & 1.8 & 7.1 \\
\hline Total & 154 & 2.9 & 66.8 & 0.5 & 3.7 & 168.2 & 0.2 \\
\hline
\end{tabular}

iance were the log-transformed estimates of the percentage of worktime spent with the trunk in flexion or rotation.

\section{Results}

The results of the measurements of percentage of worktime with trunk flexion are presented in table 3. The differences in the mean exposure to trunk flexion among the occupational groups were large. The crane operators had, on an average, a nearly sevenfold level of exposure compared with the straddle-carrier drivers.
Within each occupational group large differences were observed between the measurements of a worker's exposure to trunk flexion. These large differences were reflected in the values of the geometric standard deviations, ranging from 1.6 to 3.9 .

The measurements of the percentage of worktime with trunk rotation are summarized in table 4. Again, the differences in mean exposure to trunk rotation among the occupational groups were considerable. The crane operators showed the lowest mean exposure with an average of $3 \%$ of their worktime in trunk rotation. Among the straddle-carrier drivers a 13-fold level of 
exposure was found. Within each occupational group the measurements of a worker's exposure to trunk rotation varied greatly. The values of the geometric standard deviations ranged from 1.5 to 3.0. A notable finding was that the occupational groups were inversely ordered with respect to their mean exposures to trunk flexion and trunk rotation.

Table 5 presents the results of the one-way analysis of variance with repeated measurements. The analysis of variance for the total population, regardless of the worker's membership in different occupational groups, showed that the overall variance ratio was smaller than 1. This finding means that the betweenworker variance was greater than the within-worker variance. A similar analysis of variance for each occupational group demonstrated variance ratios ranging from 0.2 to 7.1. Among the packers the withinworker variance was markedly larger than the betweenworker variance for both trunk flexion and trunk rotation. Moreover, the geometric standard deviations of the between-worker variances in this group were small, a finding which indicates that all of the packers had experienced a similar postural load on the back. The small between-worker variances in the group of packers were also expressed in the modest values of the associated range ratios. Among the other occupational groups large values of the geometric standard deviation and the $\mathrm{R}_{0.95}$ were found. Workers within these groups were exposed to different levels of postural load due to trunk flexion and rotation. In every occupational group the geometric standard deviations appeared to be smaller than the geometric standard deviations for the total population. This finding demonstrates that the differences between the workers within an occupational group were smaller than the differences between workers in the total population. Therefore, this result indicates differences in exposure experience among the occupational groups.

In table 6 the total variability of exposure to postural load is partitioned into its different components. Both for trunk flexion and trunk rotation the estimated contribution of the variance between occupational groups was the largest source of variance. In the case of trunk flexion the between-group variance almost equaled the within-group variance, whereas for trunk rotation the between-group variance was considerably larger than the within-group variance. This analysis showed that the breakdown in occupational groups was more successful for the exposure to trunk rotation than that for the exposure to trunk flexion. Differences for individual workers between parts of the shift resulted in the second source of variance. When occupational group status was accounted for, the within-worker variance was larger than the between-worker variance.

\section{Discussion}

Exposure assessment in occupational epidemiology on back pain needs more attention $(11,20)$. A characteri-
Table 6. Estimated contribution of different sources of variance to the total variability of exposure to postural load due to trunk flexion and trunk rotation in five occupational groups.

\begin{tabular}{|c|c|c|c|}
\hline \multirow{2}{*}{ Source of variance } & \multirow{2}{*}{$\begin{array}{l}\text { Estimated } \\
\text { variance } \\
\text { component }\end{array}$} & \multicolumn{2}{|c|}{$\begin{array}{l}\text { Contribution to the } \\
\text { total variability }(\%)\end{array}$} \\
\hline & & $\begin{array}{l}\text { Trunk } \\
\text { flexion }\end{array}$ & $\begin{array}{c}\text { Trunk } \\
\text { rotation }\end{array}$ \\
\hline Between groups & $\sigma_{9}^{2}$ & 47.4 & 72.2 \\
\hline $\begin{array}{l}\text { Between workers } \\
\text { within groups }\end{array}$ & $\sigma_{w}^{2}$ & 24.1 & 11.7 \\
\hline $\begin{array}{l}\text { Between parts of shifts } \\
\text { within workers }\end{array}$ & $\sigma_{s}^{2}$ & 28.5 & 16.1 \\
\hline Total & & 100.0 & 100.0 \\
\hline
\end{tabular}

zation of exposure to postural load on the back has to take into account frequency and duration of strenuous work postures and movements, their variability during work activities within a shift and between different shifts, and the differences between workers performing the same tasks. This study was conducted to investigate sources of variability in exposure to postural load on the back and to evaluate the homogeneity of the exposure within occupational groups. The concept of postural load was restricted to nonneutral postures of the trunk in flexion and rotation. The measure of exposure was the percentage of worktime spent with the trunk in flexion or rotation. A measurement strategy with repeated measurements was applied to estimate the variability in exposure due to differences between groups, between workers, and within workers.

In this study the distributions of measurements within each occupational group were better characterized by the log-normal distribution than by the normal distribution. Adopting the log-normal model for the exposure to postural load on the back made it possible to draw inferences about this exposure and apply the well-developed theory of exposure assessment to toxic substances in air (14).

An issue not addressed explicitly in this study is the contribution of the random measurement error to the variability of exposure (ie, to the within-worker variance). Exposure measurement with an observational method is sensitive to intra- and interobserver variability. One study on observers' agreement of direct observations showed a coefficient of reliability of $81 \%$ for bending of the trunk. However, in the same study, rotation of the trunk was difficult to observe, and a reliability coefficient was found of $20 \%$ (21). Prior to this study, a limited survey was conducted with two observers who simultaneously observed seven workers for a $60-\mathrm{min}$ period. The percentage of agreement was 83 (SD 4) \% for trunk flexion and 78 (SD 11)\% for trunk rotation. Intraobserver variability cannot be assessed when a direct observation method is being applied. Under the assumption of random interobserver variability, the percentage of agreement between the two observers can be regarded as the measurement error of the observational technique. The variability 
due to random errors in the measurement technique can be represented by the coefficient of variation. The observed variability of exposure, expressed by the geometric standard deviation of the log-normally distributed measurements, can be adjusted for the variability of measurement technique, represented by the coefficient of variation of the normally distributed measurement errors (22). The relative contribution of a coefficient of variation of $20 \%$ to an observed variability of exposure of GSD $=1.50$ will be about $6 \%$. With larger values for the geometric standard deviations, the contribution of the measurement error will be negligibly small. Therefore, it is a reasonable assumption that the measurement error of the observation method used did not contribute significantly to the variability in exposure due to workplace conditions or the individual characteristics of the workers. This finding indicates that improving the reliability of the measurement method is of less importance than improving the measurement strategy.

Three approaches were used to study the classification of workers into groups with distinguishable levels of exposure. The first approach strongly focused on the homogeneity of occupational groups exposed to postural load on the back. Rappaport (14) has advocated the use of a range ratio as a quantitative measure of the uniformity of exposure across an occupational group. According to his strict definition of a homogeneous exposure group, characterized by an $\mathbf{R}_{0.95}$ range ratio of two or less, only the packers could be considered as such. The range ratios of the other groups were significantly larger, showing that workers within the same job can be differently exposed. The interindividual variability in postural load can be explained by variations in the tasks performed and the subjects' anthropometry and work methods (6). The consequence for the misclassification of exposure of substantial between-worker variance in epidemiologic surveys depends on the relative magnitude of the other sources of variability.

The second approach is based on the ratio of the between-worker variance and the within-worker variance. The variance ratio in some occupational groups showed that the contribution of the within-worker variance to the total exposure variability can surpass the influence of the between-worker variance. The poor agreement between the variance ratio and the range ratio illustrates that a large variance ratio can still imply large differences in exposure to postural load among workers of the same occupational group. The withinworker variance may be partly explained by differences in the tasks performed. The averaging time of the measurements and the number of repeated measurements can also account for the observed variability of exposure to postural load within one shift. In this study the within-shift variance was based on the short averaging time of $30 \mathrm{~min}$ and two repeated measurements only. Analogous to the measurement of chemicals in the air of a workplace (23), it can be expected that the variance of a worker's distribution of exposure to postural load decreases as the averaging time of measurement increases or the number of repeated measurements increases. This phenomenon will dampen the within-shift variation and improve the precision of the estimated mean exposure of individuals.

Heederik and his colleagues have argued that inhomogeneous groups are acceptable in epidemiologic studies unless they have overlapping exposure distributions (16). The third approach of partitioning the total exposure variability can reveal the ratio of the between-group and within-group variance. In this study the use of occupational groups could explain the variability of exposure to postural load due to trunk flexion and rotation for 47 and $72 \%$, respectively. The between-group variance was the most important source of variability of exposure in this survey. This is a desirable feature in an epidemiologic study based on a comparison of different exposure groups. The withingroup variance can be reduced by the appropriate selection of occupational groups with maximal contrast in exposure. For example, in this study the woodworking machinists appeared to have an intermediate exposure to postural load with a large within-group variance. Excluding this occupational group from the analysis of variance increased the contribution of the group component in the variability of trunk flexion and rotation to 56 and $79 \%$, respectively.

An important topic in epidemiologic studies is misclassification, either of the exposure or of the health end point. This study focused on possible sources of nondifferential misclassification of exposure to postural load on the back which will bias the relationship between postural load and (low-)back pain towards the null hypothesis (10). The analysis of the components of variability of exposure to postural load on the back may act as a guide towards appropriate measurement strategies for exposure in epidemiologic studies on lowback pain. Often, a random sample of workers of the occupational groups under study is monitored. With such an approach the between-group variance should be the principal source of variability of exposure. Unfortunately, one cannot rely on traditional methods for grouping strategies such as occupation or job title. The assumption of distinguishable exposure groups has to be evaluated; the between-group variance has to exceed the within-group variance. In the absence of distinguishable subgroups in the population under study, often characterized by a small between-worker variance, an external reference group has to be selected with maximal contrast in exposure. When confronted with a large within-worker variance, the workers of the population under study have to be monitored repeatedly or, alternatively, be monitored with an increased averaging time of measurement. In the case of individuals as the most important source of differences in exposure to postural load, the most appropriate approach would be to monitor each subject under 
study for an estimation of postural load at the individual level.

It is obvious that the choice of measurement strategy has important implications for the applicability of measurement techniques for postural load on the back. Repeated measurement of many workers during several days limits the feasibility of most observational techniques. Personal monitoring with direct measurement techniques may be required (24). Some study designs require extensive measurement programs.

Before large epidemiologic studies on low-back pain are started, information on important sources of the exposure variability is required. It has been recommended that an exposure-oriented survey be conducted prior to the start of the epidemiologic study. In such a survey multiple measurements are collected from representative workers (14). Subsequently, the partitioning of the variability of exposure into its various components provides the basis for assigning groups and the development of an adequate exposure assessment strategy (12).

\section{Acknowledgments}

The author is deeply indebted to Dr D Heederik, Mr $\mathrm{H}$ Kromhout, and Dr J Burema of the Agricultural University Wageningen, who guided the author through the concepts and pitfalls of exposure variability and associated statistical analysis.

\section{References}

1. Andersson GBJ. Epidemiologic aspects on low back pain in industry. Spine 1981;6:53-60.

2. Troup JDG. Causes, prediction and prevention of back pain at work. Scand J Work Environ Health 1984;10: 419-28.

3. Walsh K, Varnes N, Osmond C, Styles R, Coggon D. Occupational causes of low-back pain. Scand J Work Environ Health 1989;15:54-9.

4. Lindh M. Biomechanics of the lumbar spine. In: Nordin M, Frankel VH, ed. Basic biomechanics of the musculoskeletal system. Philadelphia/London: Lea \& Febiger, 1989:183-207.

5. Keyserling WM, Punnett L, Fine LJ. Trunk posture and back pain: identification and control of occupational risk factors. Appl Ind Hyg 1988;3:87-92.

6. Punnett L, Fine LJ, Keyserling WM, Herrin GD, Chaffin DB. Back disorders and nonneutral trunk postures of automobile assembly workers. Scand J Work Environ Health 1991;17:337-46.

7. Videman T, Rauhala H, Asp S, Lindström K, Cerdercreutz G, Kämppi M, et al. Patient-handling skill, back injuries, and back pain: an inventory study in nursing.
Spine $1989 ; 14: 148-56$.

8. Damkot DK, Pope MH, Lord J, Frymoyer JW. The relationship between work history, work environment and low-back pain in men. Spine 1984;9:395-9.

9. Gilad I, Kirschenbaum A. About the risks of back pain and work environment. Int J Ind Ergon 1986;1:65-74.

10. Checkoway H, Pearce NE, Crawford-Brown DJ. Research methods in occupational epidemiology. New York/Oxford: Oxford University Press, 1989.

11. Burdorf A. Exposure assessment of risk factors for disorders of the back in occupational epidemiology. Scand J Work Environ Health 1992;18:1-9.

12. Heederik D, Boleij JSM, Kromhout H, Smid T. Use and analysis of exposure monitoring data in occupational epidemiology: an example of an epidemiological study in the Dutch animal food industry. Appl Occup Environ Hyg 1991;6:458-64.

13. Chang WS, Bejjani FJ, Chyan D, Bellegarde M. Occupational musculoskeletal disorders of visual artists: a questionnaire and video analysis. Ergonomics 1987;30:3346.

14. Rappaport SM. Assessment of long-term exposures to toxic substances in air. Ann Occup Hyg 1991;35:61121.

15. Karhu O, Kansi P, Kuorinka I. Correcting working postures in industry: a practical method for analysis. Appl Ergon 1977;8:199-201.

16. Heederik D, Kromhout H, Burema J. Assessment of long-term exposure to toxic substances in air [letter]. Ann Occup Hyg 1991;35:671-673.

17. Shapiro SS, Wilk MB. An analysis of variance test for normality (complete samples). Biometrika 1965;52:591611.

18. Davies OL, Goldsmith PL. Statistical methods in research and production. 4th edition. London/New York: Longman, 1984.

19. Glantz SA, Slinker BK. Primer of applied regression and analysis of variance. New York, NY: McGraw-Hill, 1990.

20. Hagberg M. Occupational musculoskeletal disorders a new epidemiological challenge? In: Hogstedt $\mathrm{C}$, Reuterwall C, ed. Progress in occupational epidemiology. Amsterdam: Excerpta Medica, 1988:15-26.

21. Baty D, Buckle PN, Stubbs DA. Posture recording by direct observation, questionnaire assessment and instrumentation: a comparison based on a recent field study. In: Corlett N, Wilson J, ed. The ergonomics of working postures. London: Taylor and Francis, 1986: 283-92.

22. Nicas M, Simmons BP, Spear RC. Environmental versus analytical variability in exposure measurements. Am Ind Hyg Assoc J 1991;52:553-7.

23. Coenen W. Beschreibung des zeitlichen verhaltens von schadstoffkonzentrationen durch einen stetigen Markowprocess. Staub-Reinh Luft 1976;36:240-8.

24. Snijders C, Van Riel MPJM, Nordin M. Continuous measurement of spine movements in normal working situations over periods of $8 \mathrm{~h}$ or more. Ergonomics 1987;30:639-53.

Received for publication: 16 April 1992 